Article

\title{
Supercritical Regeneration of an Activated Carbon Fiber Exhausted with Phenol
}

\author{
M. Jesus Sanchez-Montero, Jennifer Pelaz, Nicolas Martin-Sanchez, Carmen Izquierdo and \\ Francisco Salvador * \\ Dpto Química-Física, Facultad de Ciencias Química, Universidad de Salamanca, Plaza de la Merced s/n, \\ 37008 Salamanca, Spain; chusan@usal.es (M.J.S.-M.); jpf@usal.es (J.P.); nicolas_martin@usal.es (N.M.-S.); \\ misiego@usal.es (C.I.) \\ * Correspondence: salvador@usal.es; Tel.: +34-677-549-970
}

Received: 27 November 2017; Accepted: 13 December 2017; Published: 9 January 2018

Featured Application: Authors are encouraged to provide a concise description of the specific application or a potential application of the work. This section is not mandatory.

\begin{abstract}
The properties of supercritical $\mathrm{CO}_{2}\left(\mathrm{SCCO}_{2}\right)$ and supercritical water (SCW) turn them into fluids with a great ability to remove organic adsorbates retained on solids. These properties were used herein to regenerate an activated carbon fiber (ACF) saturated with a pollutant usually contained in wastewater and drinking water, phenol. Severe regeneration conditions, up to 225 bar and $400{ }^{\circ} \mathrm{C}$, had to be employed in $\mathrm{SCCO}_{2}$ regeneration to break the strong interaction established between phenol and the ACF. Under suitable conditions (regeneration temperature, time, and pressure, and flow of $\mathrm{SCCO}_{2}$ ) the adsorption capacity of the exhausted ACF was completely recovered, and even slightly increased. Most of the retained phenol was removed by thermal desorption, but the extra percentage removed by extraction allowed $\mathrm{SCCO}_{2}$ regeneration to be significantly more efficient than the classical thermal regeneration methods. $\mathrm{SCCO}_{2}$ regeneration and $\mathrm{SCW}$ regeneration were also compared for the first time. The use of SCW slightly improved regeneration, although SCW pressure was thrice $\mathrm{SCCO}_{2}$ pressure. The pathways that controlled SCW regeneration were also investigated.
\end{abstract}

Keywords: supercritical carbon dioxide; supercritical water; extraction; thermal desorption

\section{Introduction}

The critical point marks a borderline above which the physical properties of a fluid suffer severe changes. Supercritical fluids have a density similar to the density of liquids, but their high diffusivity, and low viscosity and surface tension are characteristics of gases. Furthermore, they efficiently dissolve gases and organic compounds thanks to their low dielectric constant. $\mathrm{CO}_{2}$ is the most used supercritical fluid because of its mild critical constants, $\mathrm{P}_{\mathrm{c}}=73$ bar and $\mathrm{T}_{\mathrm{c}}=31^{\circ} \mathrm{C}$. Thanks to the previously described properties, supercritical $\mathrm{CO}_{2}\left(\mathrm{SCCO}_{2}\right)$ is used to extract organic compounds retained in liquids or on solid matrixes [1]. The regeneration of activated carbons (ACs) is one of the applications in which $\mathrm{SCCO}_{2}$ is used as extracting fluid.

ACs have excellent adsorbent properties that turn them into a suitable material to purify polluted gaseous and liquid streams [2]. During this process, the pollutants accumulate on the surface of the ACs and their adsorption capacity is progressively reduced until they are completely exhausted. The economical and environmental viabilities of this purification process strongly depend on the removal of the pollutants retained on the ACs and the recovery of their adsorption capacity, that is to say, on the regeneration of the ACs. Several methods to regenerate ACs exist [3,4], although the search for efficient, low-cost, and environmentally sustainable procedures continues because just a few methods gather all of these characteristics. As an example, thermal regeneration with inert gases at high 
temperatures is the most widespread method despite the damages that it causes in the structure of the ACs. Furthermore, temperatures about $700-900{ }^{\circ} \mathrm{C}$ are needed to remove strongly retained pollutants $[5,6]$.

In this context, $\mathrm{SCCO}_{2}$ regeneration arises as an interesting alternative. $\mathrm{SCCO}_{2}$ is able to flow through the porous net of the ACs, reach the micropores where the pollutants are retained, and extract them. The temperatures used in this method so far are lower than $100^{\circ} \mathrm{C}$; consequently, the energy waste is restricted regarding thermal regeneration, and the porosity of the ACs is better preserved. Furthermore, the extracted adsorbate can be easily recovered to be reused or destroyed once the $\mathrm{SCCO}_{2}$ is cooled and depressurized to atmospheric pressure. $\mathrm{SCCO}_{2}$ is usually employed to regenerate ACs saturated with volatile organic compounds like benzene [7], toluene [8-11], m-xylene [12], cyclohexane [13], or ethyl acetate [14,15]. The regeneration of ACs saturated with inorganic compounds is less usual and co-solvents must be used to efficiently extract these adsorbates [16]. The employment of $\mathrm{SCCO}_{2}$ has also been studied to regenerate ACs saturated with low-volatile organic compounds, e.g., phenol [17-19], pesticides [20], herbicides [21], or insecticides [22]. Phenol is the most common model compound in the field of regeneration of ACs [3]: it is a pollutant frequently found in wastewater and drinking water that remains strongly retained on the carbon surface of ACs. The limited number of works that have studied the $\mathrm{SCCO}_{2}$ regeneration of ACs exhausted with phenol state that, at regeneration pressures and temperatures below 200 bar and $60{ }^{\circ} \mathrm{C}$, respectively, phenol is not properly extracted [19] and the ACs are not efficiently regenerated [18].

The exhausted activated carbon fibers (ACFs) can also be regenerated using other supercritical fluids as regeneration agents, namely, supercritical water (SCW). SCW is not used as commonly as $\mathrm{SCCO}_{2}$ because of its high critical constants, $\mathrm{P}_{\mathrm{C}}=221$ bar and $\mathrm{T}_{\mathrm{C}}=374{ }^{\circ} \mathrm{C}$. These constants make SCW regeneration be an energetically more demanding method than $\mathrm{SCCO}_{2}$ regeneration; despite this drawback, it has been probed that SCW and subcritical water $\left(150\right.$ bar and $350{ }^{\circ} \mathrm{C}$ ) are able to efficiently remove phenol [23] and some of its derivates [24] from traditional ACs. Under these conditions, SCW is not only able to remove the retained pollutants but also clean and open the microporosity of the solids, hence increasing the available surface area for subsequent adsorption stages.

This work reports the regeneration of an activated carbon fiber (ACF) exhausted with phenol using $\mathrm{SCCO}_{2}$ and SCW as regenerating fluids. The porous structure of ACFs is similar to that of ACs but their physical morphology provides them with better adsorbent properties than those of ACs. They have larger surface areas because their pores are more uniform and less branched than the pores of ACs, hence their adsorption capacity is greater $[25,26]$. However, it is an expensive material so an effective regeneration method is essential to guarantee the economical viability of the purification method based on the adsorption of pollutants on ACFs. In order to meet this requirement, the regeneration conditions were hardened in this investigation, thus reaching pressure and temperature up to 225 bar and $400^{\circ} \mathrm{C}$ in $\mathrm{SCCO}_{2}$ regeneration and 300 bar and $425^{\circ} \mathrm{C}$ in SCW regeneration. The influence of other parameters (regeneration time, flow of regenerating fluid and number of subsequent adsorption-desorption cycles) on the regeneration efficiency (RE) was also analyzed as well as the ability of the method to regenerate the material after several subsequent adsorption-regeneration cycles. Taking into account the scarce information regarding SCW regeneration, this work also reports the comparison between $\mathrm{SCCO}_{2}$ regeneration and SCW regeneration of an ACF exhausted with phenol for the first time.

\section{Materials and Methods}

\subsection{Materials}

A commercial ACF cloth supplied by Kynol Europe (Hamburg, Germany) was used as the adsorbent. This ACF was prepared from the textile fiber Novoloid. The original carbon fiber was activated in a one-step process combining carbonization and activation at $900-1000{ }^{\circ} \mathrm{C}$. Phenol was purchased from Merck-Spain (Madrid, Spain) and used as received. Water was purified with a Milli-Q device (Wasserlab, Barbatáin, Navarra, Spain) before its use. $\mathrm{CO}_{2}\left(99.999 \%\right.$ purity) and $\mathrm{N}_{2}(99.999 \%$ purity) gases were supplied by Air Liquide (Madrid, Spain). 


\subsection{Adsorption-Regeneration Cycles}

The ACF was subjected to subsequent adsorption-regeneration cycles.

The adsorption step began by placing $0.18 \mathrm{~g}$ of the ACF into a home-made sample holder consisting of a cylindrical tube made of Hastelloy ( $5 \mathrm{~cm}$ in length, $\frac{1}{4}$ " OD), which was immersed in a thermostat at $27^{\circ} \mathrm{C}$. A HPLC (high performance liquid chromatography) pump model LC-10AS (Shimadzu, Kyoto, Japan) pumped a flow of $4.0 \mathrm{~cm}^{3} \cdot \mathrm{min}^{-1}$ of a $5.35 \times 10^{-4} \mathrm{M}$ phenol solution through the ACF during $240 \mathrm{~min}$. The effluent stream was monitored continuously with a spectrophotometer model UV-1603 supplied by Shimadzu, at a wavelength of $270 \mathrm{~nm}$ to obtain the phenol breakthrough curve. The amount of phenol adsorbed could be determined in two ways. On one hand, by integrating the breakthrough curve; on the other hand, by collecting all of the effluent stream and analyzing the amount of phenol contained in it. Both procedures led to the same result. The original ACF retained $162.7 \pm 19.5 \mathrm{mg}_{\text {phenol }} \cdot \mathrm{g}_{\mathrm{ACF}}{ }^{-1}$ during this adsorption step.

Once the adsorption step had been completed, the regeneration step began. Figure 1 shows the schematic of the installation used for the $\mathrm{SCCO}_{2}$ regeneration experiments.

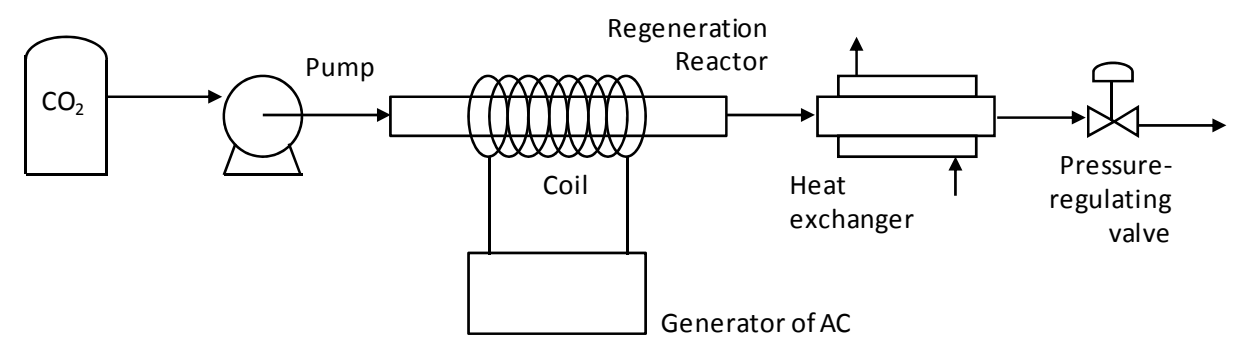

Figure 1. Schematic of the installation used for the supercritical $\mathrm{CO}_{2}\left(\mathrm{SCCO}_{2}\right)$ regeneration experiments.

The sample holder was placed into the regeneration reactor, a cylindrical tube made of Hastelloy (50 $\mathrm{cm}$ in length, $2 \mathrm{~cm}$ OD), which was placed in the middle of a cylindrical induction coil. Then, the regenerating fluid was pumped through the exhausted ACF. Liquid cooled $\mathrm{CO}_{2}$ at 50 bar and $-4{ }^{\circ} \mathrm{C}$ was pumped by a High Pressure P-Series Pump (Thar Technologies, Pittsburgh, PA, USA), a device designed to pump pressurized liquids. The effluent stream was discharged through an automatic pressure-regulating valve, which was used to control the regeneration pressure. Once the pressure had been attained, the reactor was heated by inductive heating. A generator of alternating current model Power Cube 90/180 (CEIA, Viciomaggio, Arezzo, Italy) circulated an electrical current through the coin. The magnetic field generated within the coin rapidly heated the reactor and allowed reaching the desired regeneration temperature in a few seconds. The hot effluent stream proceeding from the reactor went through a heat exchanger, where it was cooled to ambient temperature before reaching the pressure-regulating valve. This design allowed the ACF to remain into the sample holder at any time, thus avoiding any mass loss.

In $\mathrm{SCCO}_{2}$ regeneration, the temperature, time, pressure, and flow rate ranges investigated were 200-400 ${ }^{\circ} \mathrm{C}, 10-35 \mathrm{~min}, 100-225 \mathrm{bar}$, and $1-15 \mathrm{~cm}^{3} \cdot \mathrm{min}^{-1}$, respectively. The $\mathrm{SCCO}_{2}$ flow rate was referred to the conditions at which the fluid was pumped $\left(\rho_{\mathrm{CO} 2}=0.96 \mathrm{~g} \cdot \mathrm{cm}^{-3}\right)$, so that the volumetric and mass flow rates essentially agreed.

The installation used for the SCW regeneration experiments was the same; in those experiments, $\mathrm{CO}_{2}$ was replaced by water and the fluid was pumped by a HPLC pump model K-501 (Knauer, Hamburg, Germany). The SCW regeneration experiments were carried out at 300 bar and $425^{\circ} \mathrm{C}$ with a water flow of $3 \mathrm{~cm}^{3} \cdot \mathrm{min}^{-1}$. The time range investigated was $5-15 \mathrm{~min}$.

Once the ACF had been regenerated, it was exposed to a subsequent adsorption step. RE (regeneration efficiency) was calculated as follows, Equation (1):

$$
\operatorname{RE}(\%)=\left(\frac{\text { phenol adsorbed by the regenerated ACF }}{\text { phenol adsorbed by the original ACF }}\right) \cdot 100
$$




\subsection{Textural Characterization}

The ACFs were texturally characterized by $\mathrm{N}_{2}$ adsorption-desorption isotherms at $-196^{\circ} \mathrm{C}$ and $\mathrm{CO}_{2}$ adsorption isotherms at $0{ }^{\circ} \mathrm{C}$.

The $\mathrm{N}_{2}$ isotherms were obtained on a volumetric device ASAP 2010 from Micromeritics Spain (Madrid, Spain). The specific surface area $\left(\mathrm{S}_{\mathrm{BET}}\right)$ was calculated by applying the Brunauer-Emmet-Teller (BET) equation to the $\mathrm{N}_{2}$ isotherms. The micropore volume, $\mathrm{V}_{0}\left(\mathrm{~N}_{2}\right)$, was obtained by applying the Dubinin equation to the $\mathrm{N}_{2}$ isotherm. The mesopore volume $\left(\mathrm{V}_{\text {meso }}\right)$ was calculated by subtracting the value of $\mathrm{V}_{0}\left(\mathrm{~N}_{2}\right)$ from the total pore volume determined from the $\mathrm{N}_{2}$ isotherm at a relative pressure of 0.95 .

The $\mathrm{CO}_{2}$ isotherms were obtained on a volumetric device Tristar 3000 from Micromeritics Spain. The micropore volume, $\mathrm{V}_{0}\left(\mathrm{CO}_{2}\right)$, was obtained by applying the Dubinin equation to the $\mathrm{CO}_{2}$ isotherms.

\subsection{Temperature Programmed Desorption (TPD) with Pressurized Water}

This technique was used to study the nature of the adsorption of phenol on the ACF. A detailed description of the procedure can be found elsewhere [27]. In summary, a water stream pressurized at 250 bar was pumped through an exhausted ACF. The water stream was progressively heated at a $2.7^{\circ} \mathrm{C} \cdot \mathrm{min}^{-1}$ heating rate from ambient temperature up to $580^{\circ} \mathrm{C}$. The experiment lasted $205 \mathrm{~min}$. The phenol released from the ACF as the stream was heated was analyzed in a spectrophotometer at a wavelength of $270 \mathrm{~nm}$.

\section{Results and Discussion}

\subsection{Preliminary Studies: Effect of Supercritical Treatments on the Textural Properties of the ACF}

Supercritical fluids can be used to prepare ACFs $[28,29]$. In this application, supercritical fluids react with a raw carbonized fiber at temperatures above $700^{\circ} \mathrm{C}$. The fiber is gasified and its porosity is increased, hence becoming an ACF. Consequently, when the regeneration procedure of an ACF is performed with supercritical fluids, the textural properties of the ACF may be changed, which would play an important role in the recovery of the adsorption capacity. Although the temperatures at which the gasification of similar fibers begins have been previously probed to be higher than the regeneration temperatures used herein $[28,29]$, the mere exposure of the ACF to $\mathrm{CO}_{2}$ and water above their critical points may cause certain changes in its porosity.

A few experiments were made to assess the possible changes in the textural properties of the ACF when it was exposed to the supercritical fluids. The original ACF was exposed to a $\mathrm{SCCO}_{2}$ flow at 100 bar and two different temperatures, $250{ }^{\circ} \mathrm{C}\left(\mathrm{SCCO}_{2} .250\right)$ and $700{ }^{\circ} \mathrm{C}\left(\mathrm{SCCO}_{2} .700\right)$, during $180 \mathrm{~min}$; and to a SCW flow at $650^{\circ} \mathrm{C}$ and 300 bar during $180 \mathrm{~min}$ (SCW650). Table 1 shows the results obtained.

Table 1. Changes in the textural properties of the original activated carbon fiber (ACF) when it is exposed to supercritical fluids.

\begin{tabular}{cccccc}
\hline Sample & $\mathbf{S}_{\text {BET }}\left(\mathbf{m}^{\mathbf{2}} \cdot \mathbf{g}^{-\mathbf{1}}\right)$ & $\mathbf{V}_{\mathbf{0}}\left(\mathbf{N}_{\mathbf{2}}\right)\left(\mathbf{c m}^{\mathbf{3}} \cdot \mathbf{g}^{-\mathbf{1}}\right)$ & $\mathbf{V}_{\text {meso }}\left(\mathbf{c m}^{\mathbf{3}} \cdot \mathbf{g}^{-\mathbf{1}}\right)$ & $\mathbf{V}_{\mathbf{0}}\left(\mathbf{C O}_{\mathbf{2}}\right)\left(\mathbf{c m}^{\mathbf{3}} \cdot \mathbf{g}^{-\mathbf{1}}\right)$ & Mass Losses $(\mathbf{\%})$ \\
\hline Original & 1030 & 0.511 & 0.008 & 0.397 & - \\
$\mathrm{SCCO}_{2} .250$ & 1112 & 0.524 & 0.002 & 0.393 & Negligible \\
$\mathrm{SCCO}_{2} .700$ & 1300 & 0.540 & 0.001 & 0.384 & 8 \\
$\mathrm{SCW} .650$ & 1438 & 0.590 & 0.001 & 0.341 & 15 \\
\hline
\end{tabular}

The original ACF was essentially microporous, as reflected by its high $\mathrm{S}_{\mathrm{BET}}$ and micropore volumes. Although $\mathrm{SCCO}_{2}$ at $250{ }^{\circ} \mathrm{C}$ did not gasify the raw material, it was able to unblock a few pore entrances. This unblocking led the surface area to slightly increase since some micropores become accessible. When $\mathrm{SCCO}_{2}$ was heated up to $700{ }^{\circ} \mathrm{C}$, gasification began and some mass losses were registered. The textural parameters point that some narrow micropores detected by $\mathrm{CO}_{2}$ adsorption were being widened and turned into micropores with a larger diameter, as reflected by the increase in $\mathrm{V}_{0}\left(\mathrm{~N}_{2}\right)$ and $\mathrm{S}_{\mathrm{BET}}$. A similar phenomenon was observed when the original ACF was exposed to SCW at $650{ }^{\circ} \mathrm{C}$. 
SCW is a more reactive gasification agent than $\mathrm{SCCO}_{2}$ and because of that both the mass losses and the increases in $\mathrm{V}_{0}\left(\mathrm{~N}_{2}\right)$ and $\mathrm{S}_{\mathrm{BET}}$ were higher than in the previous case, although the temperature was lower.

The results of Table 1 may encourage regenerating the ACF at high temperatures: phenol would be removed more efficiently and the adsorption capacity of the regenerated material would be enlarged thanks to the increase in $\mathrm{S}_{\mathrm{BET}}$. However, this approach is not advisable because of the induced mass losses. The regeneration method must be applicable in several consecutive cycles. If the ACF was regenerated several consecutive times, it would progressively lose a meaningful amount of mass, what may cause a collapse of the material [30].

\section{2. $\mathrm{SCCO}_{2}$ Regeneration}

\subsubsection{Effect of Temperature}

$\mathrm{SCCO}_{2}$ flows of $3 \mathrm{~cm}^{3} \cdot \mathrm{min}^{-1}$ at 100 bar were circulated through exhausted samples of ACF during $15 \mathrm{~min}$ to study the effect of temperature on the regeneration. Four temperatures were assayed, 200, 250,300 , and $400{ }^{\circ} \mathrm{C}$. The samples were exposed to two consecutive adsorption-regeneration cycles at each temperature. Figure 2 shows the phenol breakthrough curves for the original ACF and the sample regenerated at $250^{\circ} \mathrm{C}$ after the first and the second cycle.

The curve for the sample regenerated once almost overlapped the curve for the original ACF, suggesting that, under these regeneration conditions, the original adsorption rate and capacity of the ACF were essentially preserved after one cycle. However, the curve for the sample regenerated twice was displaced towards the left side. This trend pointed that the ACF was able to adsorb a smaller amount of phenol after the second regeneration. This fact was confirmed when the REs were calculated, Figure 3.

The ACF recovered $97.8 \%$ of its original adsorption capacity when it was regenerated once at $250{ }^{\circ} \mathrm{C}$. The recovery of the original adsorption capacity was reduced to $93.5 \%$ when the regenerated ACF was saturated again, and regenerated at this temperature.

Temperature has two opposite effects on $\mathrm{SCCO}_{2}$ regeneration, which are related to the mechanistic pathways involved in the process [11,19]. $\mathrm{SCCO}_{2}$ can remove a retained pollutant through two pathways: thermal desorption and extraction. Desorption phenomenon implies the supply of an amount of thermal energy (heating of the adsorbent) large enough to break the interactions established between the adsorbate and the adsorbent; in this way, regeneration is improved when high temperatures are used. On the other hand, the increase of the regeneration temperature diminishes the density of the supercritical fluid. A lower density means the reductions of the solubility of phenol in $\mathrm{SCCO}_{2}$ and the ability of the supercritical fluid to extract the pollutant. Considering this, regeneration is worsened when high temperatures are used.

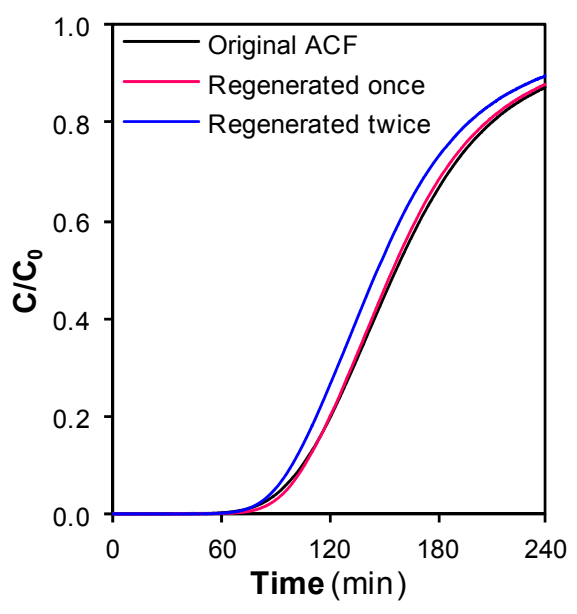

Figure 2. Phenol breakthrough curves for the original activated carbon fiber (ACF) and the sample regenerated with $\mathrm{SCCO}_{2}$ at $250^{\circ} \mathrm{C}$ after the first and the second adsorption-regeneration cycle. 


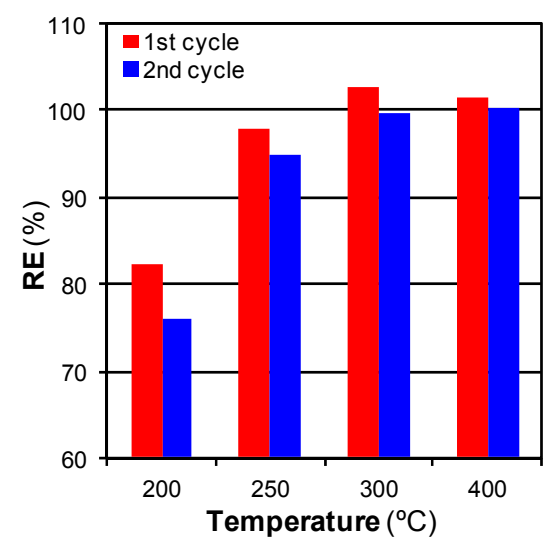

Figure 3. Effect of temperature and the number of adsorption-regeneration cycles on RE (regeneration efficiency).

Despite the meaningful reduction in the density of $\mathrm{SCCO}_{2}\left(\rho_{100 \mathrm{bar}, 200{ }^{\circ} \mathrm{C}}=0.122 \mathrm{~g} \cdot \mathrm{cm}^{-3}\right.$; $\left.\rho_{100 \mathrm{bar}, 400{ }^{\circ} \mathrm{C}}=0.079 \mathrm{~g} \cdot \mathrm{cm}^{-3}\right)$, Figure 3 shows that the thermal effect prevailed under the conditions studied herein. RE progressively increased when $\mathrm{SCCO}_{2}$ was heated from 200 to $300{ }^{\circ} \mathrm{C}$; an overheating up to $400{ }^{\circ} \mathrm{C}$ did not lead to an increase in RE. Consequently, $400{ }^{\circ} \mathrm{C}$ was the highest temperature explored in $\mathrm{SCCO}_{2}$ regeneration since under these conditions regeneration was already complete and higher temperatures might cause structural damages in the ACF.

The RE at $200{ }^{\circ} \mathrm{C}$ hardly exceeded $80 \%$. Studying how phenol was adsorbed on the ACF gave more information about why the regeneration was not complete. The nature of the adsorption of phenol on the ACF used herein was studied by TPD using pressurized water as the carrier fluid, Figure 4.

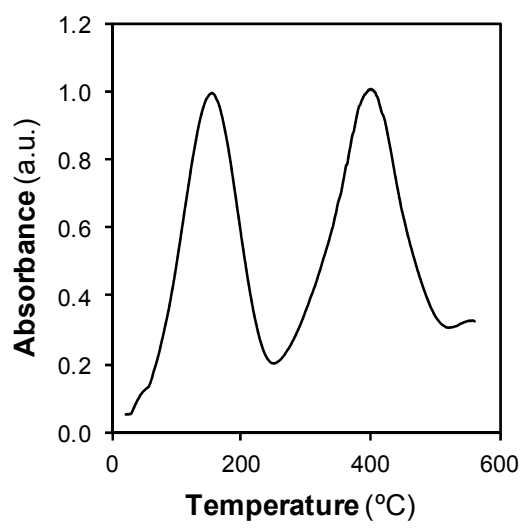

Figure 4. Desorption thermogram of phenol from the ACF using pressurized water as the carrier fluid.

The thermogram showed two peaks. The first peak appeared at temperature between 100 and $250{ }^{\circ} \mathrm{C}$, in the liquid water region. The second peak appeared above $350{ }^{\circ} \mathrm{C}$, in the SCW region. Similar results have been obtained when the nature of the adsorption of phenol on other carbon materials was studied [23], even when the characterization was made with the classical TPD with inert gas as the carrier [6,31]. The two peaks were associated to different interactions between phenol and the ACF. The first peak was removed at low temperature because that fraction established a weak physical interaction with the adsorbent. This fraction is known as physisorbed phenol. The second peak was related to a fraction of phenol that needed more energy to be removed. In that case, a strong chemical interaction was established between the adsorbent and the adsorbate. This fraction is known as chemisorbed phenol. The removal of this fraction is the main challenge to achieve an efficient regeneration. 
It seems probable that, under relatively mild conditions, $200^{\circ} \mathrm{C}$, the strongly retained chemisorbed phenol was not completely removed. The textural characterization of the regenerated ACFs allowed delving into this phenomenon. Figure 5 shows the $\mathrm{N}_{2}$ adsorption-desorption isotherms for the ACFs regenerated at the lowest and the highest temperatures investigated, as well as for the original ACF.

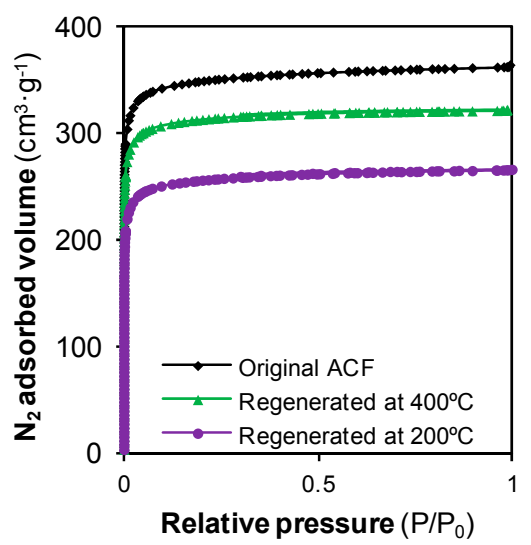

Figure 5. $\mathrm{N}_{2}$ adsorption-desorption isotherms for the original $\mathrm{ACF}$ and the ACFs regenerated at $200{ }^{\circ} \mathrm{C}$ and $400{ }^{\circ} \mathrm{C}$.

Due to the incomplete removal of phenol at $200{ }^{\circ} \mathrm{C}$, the surface area available for the subsequent adsorption was reduced (recovery of $\mathrm{S}_{\mathrm{BET}}=73 \%$ ), which explained why the regenerated ACF did not fully recover its adsorption capacity. Further accumulation of phenol happened after a second adsorption step, thus leading the ACF regenerated twice at $200{ }^{\circ} \mathrm{C}$ to lose about $25 \%$ of its original adsorption capacity.

The ACFs treated at 300 and $400{ }^{\circ} \mathrm{C}$ adsorbed a greater amount of phenol after being regenerated than in their original form, as shown by the RE values over $100 \%$. The high efficiency of the method under these conditions was preserved even when the ACF was exposed to two consecutive adsorption-regeneration cycles: the ACFs regenerated twice had the same adsorption capacity than the original ACF.

The slight increase in the adsorption capacity regarding the original ACF can be partially explained by the results of Table 1 . Under these conditions, $\mathrm{SCCO}_{2}$ removed the retained phenol and unblocked the entrance of a few pores, but Figure 5 shows that the $\mathrm{N}_{2}$ isotherm for the ACF regenerated at $400{ }^{\circ} \mathrm{C}$ was below the isotherm for the original ACF. Namely, with the treatment at $400{ }^{\circ} \mathrm{C}$ only $90 \%$ of the original $\mathrm{S}_{\mathrm{BET}}$ was recovered. However, another phenomenon was occurring during the regeneration that may also be contributing to that increase. The surface chemistry of the adsorbent also plays a key role in the adsorption phenomenon. The adsorption of phenol and its derivates is hindered by the presence of oxygen-containing surface groups [32,33]. On the other hand, it has been probed that the surface chemistry of carbon materials is modified when they are exposed to supercritical fluids. The exposure of this ACF to a $\mathrm{SCCO}_{2}$ flow at 100 bar and $250{ }^{\circ} \mathrm{C}$ removes about $60 \%$ of the carboxylic acid surface groups of the material, and this percentage increases with temperature [34]. Consequently, it is possible that the surface chemistry of the regenerated ACFs was more suitable for phenol adsorption than that of the original ACF. The combination of the probed notable recovery of the textural properties and a possible suitable modification of the surface chemistry may clarify why RE reached values above $100 \%$.

There is not an unanimous conclusion about the effect of temperature on supercritical regeneration. Some authors affirm that density is the controlling parameter at pressures just above the critical pressure, and regeneration gets worse with increasing temperatures $[7,14,15]$. It is also stated that as the fluid is compressed, viscosity becomes progressively more influential and the negative effect of temperature is then mitigated $[7,9,14,15]$. 
It must be noted that, in all of these previous works, the influence of the extraction pathway was outstanding regarding the influence of the thermal desorption pathway because temperatures did not exceed $100{ }^{\circ} \mathrm{C}$. In the current research the influence of the thermal desorption pathway is evidently more noticeable since temperatures above $200{ }^{\circ} \mathrm{C}$ are used. Thermal desorption is the main pathway when the exhausted adsorbents are regenerated with hot inert gases at temperatures lower than $300{ }^{\circ} \mathrm{C}$ [3]. Regeneration with hot inert gases is an easier procedure than $\mathrm{SCCO}_{2}$ regeneration. Consequently, it is important to study the relative influence of each pathway in $\mathrm{SCCO}_{2}$ regeneration at high temperatures to assess if the use of the supercritical fluid is necessary, or the adsorbents would be efficiently regenerated with a simple flow of a hot inert gas. This point was studied by regenerating an exhausted ACF with a $\mathrm{N}_{2}$ flow of $300 \mathrm{~cm}^{3} \cdot \mathrm{min}^{-1}$ during $15 \mathrm{~min}$ at $250{ }^{\circ} \mathrm{C}$. The RE after two adsorption-regeneration cycles with the hot inert gas was $79.2 \%$, in comparison to $93.5 \%$ with $\mathrm{SCCO}_{2}$ regeneration with the same conditions of temperature and time in both samples. The RE achieved by thermal desorption with hot inert gases was not low, but the concomitant extraction pathway related to the supercritical fluid provided a meaningful improvement that turned $\mathrm{SCCO}_{2}$ regeneration into a highly efficient regeneration method.

\subsubsection{Mass Transfer Limitations: Effect of Time, Flow, and Pressure}

Whereas the thermal desorption pathway is exclusively affected by the chosen regeneration temperature, the extraction pathway is affected by other parameters apart from temperature. Within the previous section the importance of the extraction pathway in $\mathrm{SCCO}_{2}$ regeneration has been probed, hence the search for those conditions which optimize this pathway is mandatory. An extraction step just becomes efficient when the limitations to the mass transfer are overcome. This overcoming is critical when the aimed compound is retained on highly microporous materials such as the ACF used herein. The majority of adsorption active sites are located on inner narrow micropores. This implies large mass transfer limitations, but the supercritical fluid must be able to reach those difficulty accessible zones to extract the phenol. Regeneration time, flow, and pressure can be properly modified to overcome these limitations.

Figure 6 shows the effect of time on $\mathrm{RE}$ for regeneration at 100 bar and $250{ }^{\circ} \mathrm{C}$ with a $\mathrm{SCCO}_{2}$ flow of $3 \mathrm{~cm}^{3} \cdot \mathrm{min}^{-1}$.

$\mathrm{RE}$ increased with time when the regeneration step was prolonged from 10 to $15 \mathrm{~min}$. It is commonly admitted that the penetration of $\mathrm{SCCO}_{2}$ in porous solids is easy and rapid. These results can be attributed to an external film resistance that slowed down the rate at which phenol could enter the bulk flowing fluid and be carried out of the adsorbent [22]. As the regeneration experiments were lengthened from 10 to $15 \mathrm{~min}$, phenol had more time to diffuse and reach the fluid. Greater amounts of phenol were removed from the micropores, hence improving the efficiency of the method. Further prolongation did not lead to changes in RE; this parameter described a plateau over $15 \mathrm{~min}$.

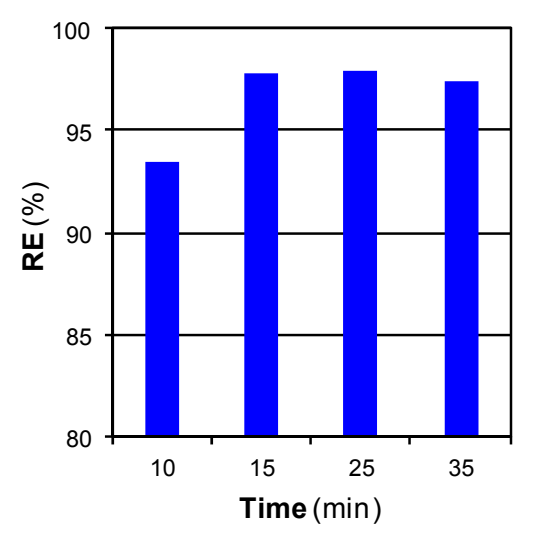

Figure 6. Effect of time on RE for regeneration at 100 bar and $250{ }^{\circ} \mathrm{C}$ with a $\mathrm{SCCO}_{2}$ flow of $3 \mathrm{~cm}^{3} \cdot \mathrm{min}^{-1}$. 
From a technical point of view, the access of $\mathrm{SCCO}_{2}$ to the inner micropores does not mean a problem for the regeneration procedure, in contrast to other regeneration methods like solvent regeneration or $\mathrm{NaOH}$ regeneration. In these methods, a rinse step must be carried out between the regeneration and the adsorption steps because the presence of the regenerating agent within the structure of the adsorbent hinders the subsequent adsorption [35-38]. In a similar way to $\mathrm{SCCO}_{2}$ regeneration, the regenerating agents must reach all the micropores to efficiently regenerate the exhausted adsorbents, what makes the rinse step trickier. This rinse step is not necessary to the method reported in this work: once the adsorbent is depressurized and cooled, the remaining $\mathrm{CO}_{2}$ turns into gas and leaves the structure of the adsorbent on its own.

Figure 7 shows the effect of the $\mathrm{SCCO}_{2}$ flow on RE for regeneration at 100 bar and $200{ }^{\circ} \mathrm{C}$ during $15 \mathrm{~min}$.

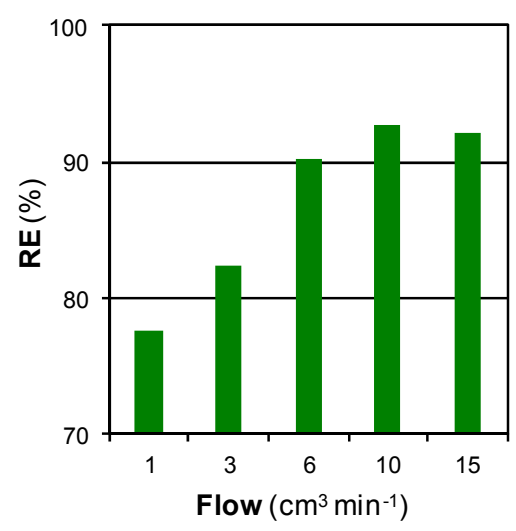

Figure 7. Effect of the $\mathrm{SCCO}_{2}$ flow on $\mathrm{RE}$ for $\mathrm{SCCO}_{2}$ regeneration at 100 bar and $200{ }^{\circ} \mathrm{C}$ during $15 \mathrm{~min}$.

RE increased with the $\mathrm{SCCO}_{2}$ flow from 1 to $10 \mathrm{~cm}^{3} \cdot \mathrm{min}^{-1}$ and remained unchanged when greater flows were used. The increase of RE with the regeneration flow is characteristic of solubility limited processes. Desorption at flow rates lower than $10 \mathrm{~cm}^{3} \cdot \mathrm{min}^{-1}$ was primarily influenced by adsorption equilibrium constraints. The effluent concentration was fixed for each flow and it increased as greater amounts of $\mathrm{SCCO}_{2}$ were pumped. Above $10 \mathrm{~cm}^{3} \cdot \mathrm{min}^{-1}$, such high flows were pumped that the equilibrium was not achieved, and the use of greater flows did not lead to the removal of greater amounts of phenol. Above that flow, the process was no longer limited by solubility but mass transfer limited. This effect of $\mathrm{SCCO}_{2}$ flow agreed with that reported by other authors [14,15,22].

Pressure is the last parameter that affects the mass transfers in an extraction step. Figure 8 shows the effect of pressure on regeneration at $200{ }^{\circ} \mathrm{C}$ during $15 \mathrm{~min}$ with a $\mathrm{SCCO}_{2}$ flow of $3 \mathrm{~cm}^{3} \cdot \mathrm{min}^{-1}$.

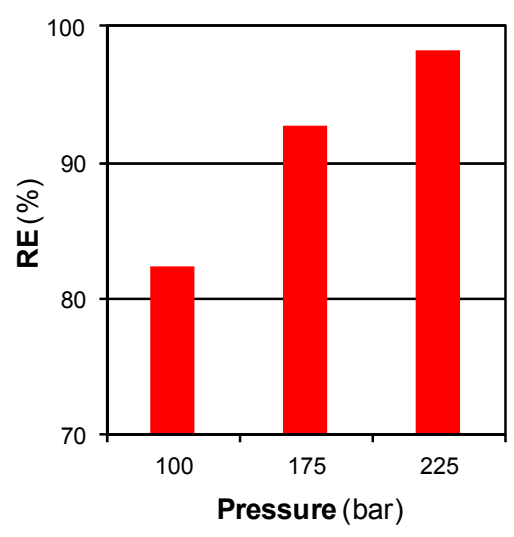

Figure 8. Effect of pressure on $\mathrm{RE}$ for $\mathrm{SCCO}_{2}$ regeneration at $200{ }^{\circ} \mathrm{C}$ with a $\mathrm{SCCO}_{2}$ flow of $3 \mathrm{~cm}^{3} \cdot \mathrm{min}^{-1}$ during $15 \mathrm{~min}$. 
As $\mathrm{SCCO}_{2}$ was more pressurized, the regenerated ACF recovered a greater percentage of its original adsorption capacity. The process was limited by solubility under the conditions used in this specific study. The solubility of phenol in $\mathrm{SCCO}_{2}$ increased as the fluid was pressurized and, as a consequence, the extraction pathway was also improved $[10,13,17]$.

This last study reveals that pressure modification may be the most interesting way to optimize $\mathrm{SCCO}_{2}$ regeneration. At $200{ }^{\circ} \mathrm{C}$ and a pressure high enough the $\mathrm{ACF}$ are effectively regenerated. Although it is still an energy-demanding temperature, it means a noticeable reduction of the energy requirements in comparison with the classical thermal regeneration carried out at temperatures above $700{ }^{\circ} \mathrm{C}$. Furthermore, it neither requires an excessive waste of regenerating fluid. The necessity for devices made with special materials able to support high pressures and the energy waste needed to work at pressures are their major drawbacks. In this way, the compression of the fluid must be controlled: an optimal pressure will exist above which the increase in solubility will be negligible [22].

\subsection{Comparison between $\mathrm{SCCO}_{2}$ Regeneration and SCW Regeneration}

In order to make a strict comparison, $\mathrm{SCW}$ regeneration was first carried out at the only temperature within the $\mathrm{SCCO}_{2}$ regeneration studies that was over the critical point of water, $400{ }^{\circ} \mathrm{C}$. However, the process was unstable because this temperature was too close to the critical temperature of water, and in this region the physical properties of the fluid suffer strong alterations. The SCW regeneration assays were finally carried out at $425^{\circ} \mathrm{C}$. Figure 9 shows the effect of time and the number of adsorption-regeneration cycles on SCW regeneration at 300 bar and $425^{\circ} \mathrm{C}$ with a SCW flow of $3 \mathrm{~cm}^{3} \cdot \mathrm{min}^{-1}$.

SCW regeneration also arose as a method able to completely recover, and even increase (RE values greater than $100 \%$ ), the adsorption capacity of the original ACF. This increase was caused by the same phenomena than in the case of $\mathrm{SCCO}_{2}$. SCW also opened a few pore entrances and modified the surface chemistry in such a way [34] that the regenerated ACF adsorbed a greater amount of phenol than the original ACF. The high efficiency of the method allowed preserving the adsorption capacity after three cycles, although a slight decrease in RE was observed when the ACF was regenerated during $5 \mathrm{~min}$. When the regeneration step was lengthened to $15 \mathrm{~min}$, RE values were higher. The effects caused by the two phenomena previously described were more remarkable for longer regeneration times, hence leading to a $5 \%$ increase in the adsorption capacity of the original ACF. We did not explore temperatures above $425^{\circ} \mathrm{C}$ in SCW regeneration since at this temperature the regeneration was already complete and higher temperatures might cause structural damages in the ACFs.

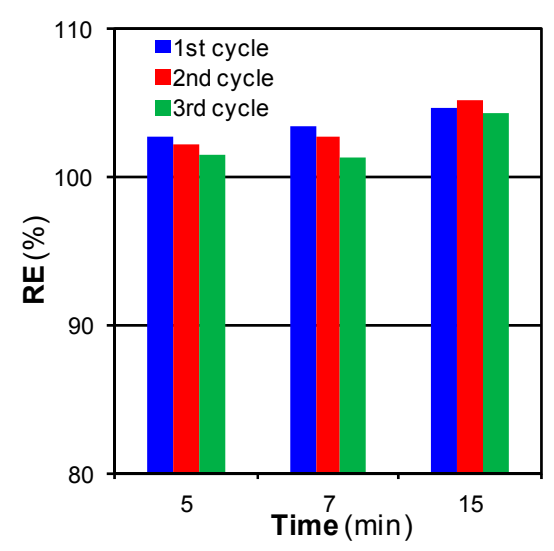

Figure 9. Effect of time and the number of adsorption-regeneration cycles on RE for supercritical water (SCW) regeneration at $300 \mathrm{bar}$ and $425^{\circ} \mathrm{C}$ with a SCW flow of $3 \mathrm{~cm}^{3} \cdot \mathrm{min}^{-1}$.

Consequently, SCW regeneration could be described as a method slightly more efficient than

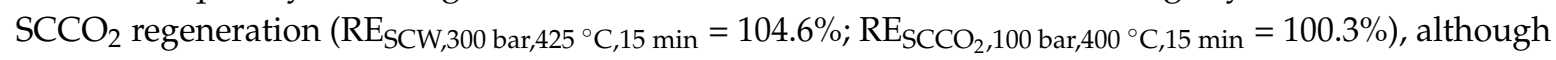
it must be noted that $\mathrm{SCW}$ pressure was thrice $\mathrm{SCCO}_{2}$ pressure. 
SCW regeneration assays were also interesting from another point of view. Novel information about the regeneration mechanism could be obtained by analyzing the effluent aqueous stream proceeding from the regeneration reactor. The effluent was divided in three samples which were collected during different stages of the regeneration step: beginning stage, intermediate stage and final stage. Each sample was analyzed by UV-Vis spectrophotometry. Figure 10 shows the spectra for the three samples collected during a 7 min regeneration assay, as well as the spectrum for the original phenol solution. The samples were highly concentrated and they had to be diluted in order to fulfill the requirements of the Lambert-Beer law. The dilutions were as follows: 1:40 for the first sample, 1:20 for the second sample, and 1:4 for the third sample.

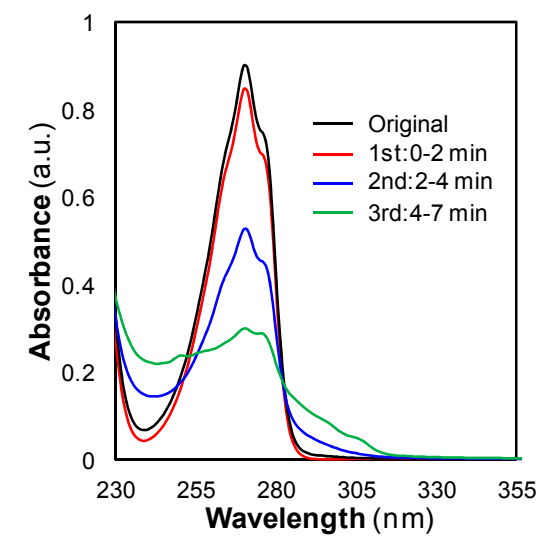

Figure 10. Spectra for the original phenol solution and the three samples collected during a SCW regeneration assay.

The spectra for the samples collected during the first 2 min of the treatment, and between minutes 2 to 4 , had a similar shape to that for the phenol solution. This similarity meant that during the first $4 \mathrm{~min}$ the phenol was removed in its original form (without any degradation). This fact pointed to the same regeneration pathways that governed $\mathrm{SCCO}_{2}$ regeneration: thermal desorption and extraction. Taking into account the dilutions, the number of moles of phenol contained in these two samples was calculated. $93 \%$ of the adsorbed phenol was removed during the first $4 \mathrm{~min}$.

On the other hand and regardless of the evident lower signal, the spectrum for the sample collected during the final 3 min showed a significantly different shape from that for the phenol solution. It also showed the typical peak at $270 \mathrm{~nm}$ and the shoulder at $275 \mathrm{~nm}$, but its signal did not tend to zero as fast as the phenol spectrum at higher wavelengths. At wavelengths lower than $270 \mathrm{~nm}$, it neither described the marked decrease of phenol spectrum and even a new peak appeared at about $250 \mathrm{~nm}$. This dissimilarity meant that other species were present in the sample besides phenol. The ability of SCW to degrade and gasify phenol has been reported [39]. At high temperatures, $700{ }^{\circ} \mathrm{C}$, and reaction times long enough, the supercritical fluid turns a fraction of this pollutant into gases. Some of the formed by-products are polycyclic aromatic hydrocarbons like naphthalene and phenanthrene, products whose UV-Vis spectra are similar to that for the sample collected during the last minutes of the SCW regeneration treatment. Consequently and despite using low temperatures, the data in Figure 10 suggested that a fraction of the retained phenol was turned into these products. This implied a minor third regeneration pathway in the mechanism of SCW regeneration, a degradation pathway, through which the remaining phenol was removed.

Some authors who have studied the regeneration of carbon adsorbents exhausted with phenol using inert gases at high temperatures, $700-900{ }^{\circ} \mathrm{C}$, state that due to the strength of the bond between the chemisorbed phenol and the adsorbent, the decomposition of that fraction is energetically less exigent than its desorption [6,31]. That is to say, chemisorbed phenol must be degraded to be removed when that method is used. The data reported herein also point that, although great amounts of phenol are removed without degradation thanks to the heating and extractive power of $\mathrm{SCW}$, a fraction of 
phenol, probably related to the chemisorbed phenol, must also be degraded to be removed. This makes a question about $\mathrm{SCCO}_{2}$ regeneration mechanism arise. The obtained results probed that phenol was removed more efficiently at high temperatures. This trend could be favored by the degradation of a fraction of the chemisorbed phenol at high temperatures, which low-temperature $\mathrm{SCCO}_{2}$ was not able to degrade. However, the effluent gaseous streams from $\mathrm{SCCO}_{2}$ regeneration could not be analyzed and the possible participation of this third regeneration pathway could not be confirmed or denied for this method. Future work could provide a device to recover the extracted pollutants, which would allow studying the mechanism that governs $\mathrm{SCCO}_{2}$ regeneration more in depth; in that way, higher temperatures may also be explored to try to highlight this pathway.

\section{Conclusions}

The $\mathrm{SCCO}_{2}$ regeneration of an $\mathrm{ACF}$ exhausted with phenol was carried out under the most severe conditions assayed so far, $225 \mathrm{bar}$ and $400^{\circ} \mathrm{C}$. The method efficiently recovered the adsorption capacity of the original ACF when regeneration temperatures were high enough, even after a few subsequent adsorption-regeneration cycles. Under certain conditions, $\mathrm{SCCO}_{2}$ modified both the textural properties and the surface chemistry of the regenerated ACF in such a way that it adsorbed greater amounts of phenol than the original ACF. Phenol was removed from the micropores through two pathways. Most of the phenol was removed because of the heating suffered by the ACF when it was exposed to the high-temperature $\mathrm{SCCO}_{2}$; however, a certain percentage of phenol was removed by extraction, a pathway that hot inert gases could not provide and which turned $\mathrm{SCCO}_{2}$ regeneration in a highly efficient method. The regeneration parameters time, flow of $\mathrm{SCCO}_{2}$, and pressure, were modified to study their influence on RE and improve it. The performances of $\mathrm{SCCO}_{2}$ and $\mathrm{SCW}$ as regenerating fluids were also compared. SCW regeneration was slightly more efficient than $\mathrm{SCCO}_{2}$ regeneration, although this method needs for a pressure three times greater. A third pathway, the degradation of a fraction of the chemisorbed phenol, was identified in the mechanism that governed SCW regeneration.

Acknowledgments: Financial support from the Spanish Ministerio de Economía y Competitividad (Project CTQ2015-64339-R) and Anticipos Fondos Feder is acknowledged.

Author Contributions: M. Jesus Sanchez-Montero and Jennifer Pelaz conceived, designed, and performed the experiments; M. Jesus Sanchez-Montero and Nicolas Martin-Sanchez analyzed the data, and wrote the paper; Francisco Salvador and Carmen Izquierdo built the home-made facilities, and supervised the whole study.

Conflicts of Interest: The authors declare no conflict of interest.

\section{References}

1. Souza-Machado, B.A.; Gambini-Pereira, C.; Baptista-Nunes, S.; Ferreira-Padilha, F.; Umsza-Guez, M.A. Supercritical fluid extraction using $\mathrm{CO}_{2}$ : Main applications and future perspectives. Sep. Sci. Technol. 2013, 48, 2741-2760. [CrossRef]

2. Ahmed, M.J. Preparation of activated carbons from date (Phoenix dactylifera L.) palm stones and application for wastewater treatments: Review. Process Saf. Environ. Prot. 2016, 102, 168-182. [CrossRef]

3. Salvador, F.; Martin-Sanchez, N.; Sanchez-Hernandez, R.; Sanchez-Montero, M.J.; Izquierdo, C. Regeneration of carbonaceous adsorbents. Part I: Thermal regeneration. Microporous Mesoporous Mater. 2015, 202, 259-276. [CrossRef]

4. Salvador, F.; Martin-Sanchez, N.; Sanchez-Hernandez, R.; Sanchez-Montero, M.J.; Izquierdo, C. Regeneration of carbonaceous adsorbents. Part II: Chemical, Microbiological and Vacuum Regeneration. Microporous Mesoporous Mater. 2015, 202, 277-296. [CrossRef]

5. Wang, J.H.; Smith, J.M. Thermal regeneration of the phenol-carbon system. AIChE J. 1985, 31, 496-498. [CrossRef]

6. Moreno-Castilla, C.; Rivera-Utrilla, J.; Joly, J.P.; López-Ramón, M.V.; Ferro-García, M.A.; Carrasco-Marín, F. Thermal regeneration of an activated carbon exhausted with different substituted phenols. Carbon 1995, 33, 1417-1423. [CrossRef] 
7. Tan, C.S.; Liou, D.C. Supercritical regeneration of activated carbon loaded with benzene and toluene. Ind. Eng. Chem. Res. 1989, 28, 1222-1226. [CrossRef]

8. Tan, C.S.; Liou, D.C. Regeneration of activated carbon loaded with toluene by supercritical carbon dioxide. Sep. Sci. Technol. 1989, 24, 111-127. [CrossRef]

9. Ryu, Y.K.; Kim, K.L.; Lee, C.H. Adsorption and desorption of $n$-hexane, methyl ethyl ketone, and toluene on an activated carbon fiber from supercritical carbon dioxide. Ind. Eng. Chem. Res. 2000, 39, 2510-2518. [CrossRef]

10. Takahashi, N.; Ushiki, I.; Hamabe, Y.; Sato, Y.; Inomata, H. Measurement and prediction of desorption behavior of five volatile organic compunds (acetone, $n$-hexane, methanol, toluene, and $n$-decane) from activated carbon for supercritical carbon dioxide regeneration. J. Supercrit. Fluids 2016, 107, 226-233. [CrossRef]

11. Ushiki, I.; Kikuchi, K.; Takahashi, N.; Sato, Y.; Ito, Y.; Inomata, H. Desorption behavior of various volatile organic compounds from activated carbon in supercritical carbon dioxide: Measurement and kinetic modeling. J. Supercrit. Fluids 2017, 121, 41-51. [CrossRef]

12. Benkhedda, J.; Jaubert, J.N.; Barth, D.; Zetzl, C.; Brunner, G. Adsorption and desorption of $m$-xylene from supercritical carbon dioxide on activated carbon. Sep. Sci. Technol. 2001, 36, 2197-2211. [CrossRef]

13. Heidari, A.; Lotfollahi, M.N.; Baseri, H. Regeneration of activated carbon loaded with cyclohexane using supercritical carbon dioxide: Experimental results and modeling. Chem. Eng. Technol. 2013, 36, 315-322. [CrossRef]

14. Srinivasan, M.P.; Smith, J.M.; McCoy, B.J. Supercritical fluid desorption from activated carbon. Chem. Eng. Sci. 1990, 45, 1885-1895. [CrossRef]

15. Tan, C.S.; Liou, D.C. Desorption of ethyl acetate from activated carbon by supercritical carbon dioxide. Ind. Eng. Chem. Res. 1988, 27, 988-991. [CrossRef]

16. Liang, M.T.; Liang, R.C.; Lin, C.H. Regeneration of cobalt-contaminated activated carbon by supercritiacl carbon dioxide extraction. Adsorption 2012, 18, 461-467. [CrossRef]

17. Chihara, K.; Oomori, K.; Oono, T.; Mochizuki, Y. Supercritical $\mathrm{CO}_{2}$ regeneration of activated carbon loaded with organic adsorbates. Water Sci. Technol. 1997, 35, 261-268.

18. Humayun, R.; Karakas, G.; Dahlstrom, P.R.; Ozkan, U.S.; Tomasko, D.L. Supercritical fluid extraction and temperature-programmed desorption of phenol and Its oxidative coupling products from activated carbon. Ind. Eng. Chem. Res. 1998, 37, 3089-3097. [CrossRef]

19. Carmona, M.; Garcia, M.T.; Carnicer, A.; Madrid, M.; Rodriguez, J.F. Adsorption of phenol and chlorophenols onto granular activated carbon and their desorption by supercritical $\mathrm{CO}_{2}$. J. Chem. Technol. Biotechnol. 2014, 89, 1660-1667. [CrossRef]

20. Madras, G.; Erkey, C.; Akgerman, A. Supercritical fluid regeneration of activated carbon loaded with heavy molecular weight organics. Ind. Eng. Chem. Res. 1993, 32, 1163-1168. [CrossRef]

21. Taylor, P.N.; Lester, J.N. Rapid extraction of isoproturon and diuron from granular activated carbon. Chemosphere 1996, 33, 1227-1240. [CrossRef]

22. Macnaughton, S.J.; Foster, N.R. Supercritical adsorption and desorption behavior of DDT on activated carbon using carbon dioxide. Ind. Eng. Chem. Res. 1995, 34, 275-282. [CrossRef]

23. Salvador, F.; Martin-Sanchez, N.; Sanchez-Montero, M.J.; Montero, J.; Izquierdo, C. Regeneration of activated carbons contaminated by phenol using supercritical water. J. Supercrit. Fluids 2013, 74, 1-7. [CrossRef]

24. Rivera-Utrilla, J.; Ferro-García, M.A.; Bautista-Toledo, I.; Sánchez-Jiménez, C.; Salvador, F.; Merchán, M.D. Regeneration of ortho-chlorophenol-exhausted activated carbons with liquid water at high pressure and temperature. Water Res. 2003, 37, 1905-1911. [CrossRef]

25. Das, D.; Gaur, V.; Verma, N. Removal of volatile organic compound by activated carbon fiber. Carbon 2004, 42, 2949-2962. [CrossRef]

26. Liu, Q.S.; Zheng, T.; Wang, P.; Jiang, J.P.; Li, N. Adsorption isotherm, kinetic and mechanism studies of some substituted phenols on activated carbon fibers. Chem. Eng. J. 2010, 157, 348-356. [CrossRef]

27. Salvador, F.; Merchán, M.D. A simple apparatus for studies of thermoprogrammed desorption in solution. Langmuir 1992, 8, 1226-1229. [CrossRef]

28. Sanchez-Montero, M.J.; Salvador, F.; Izquierdo, C. Reactivity and Porosity of a Carbon Fiber Activated with Supercritical $\mathrm{CO}_{2}$. J. Phys. Chem. C 2008, 112, 4991-4999. [CrossRef] 
29. Salvador, F.; Sánchez Montero, M.J.; Montero, J.; Izquierdo, C. Activated carbon fibers prepared from a phenolic fiber by supercritical water and steam activation. J. Phys. Chem. C 2008, 112, 20057-20064. [CrossRef]

30. Montero, J.; de la Casa-Lillo, M.A.; Sanchez-Montero, M.J.; Martin-Sanchez, N.; Izquierdo, C.; Salvador, F. Effect of supercritical fluid activation on the diameter of carbon fibres. J. Supercrit. Fluids 2015, 101, 131-139. [CrossRef]

31. Suzuki, M.; Misic, D.M.; Koyama, O.; Kawazoe, K. Study of thermal regeneration of spent activated carbons: Thermogravimetric measurement of various single component organics loaded on activated carbons. Chem. Eng. Sci. 1978, 33, 271-279. [CrossRef]

32. Franz, M.; Arafat, H.A.; Pinto, N.G. Effect of chemical surface heterogeneity on the adsorption mechanism of dissolved aromatics on activated carbon. Carbon 2000, 38, 1807-1817. [CrossRef]

33. Sabio, E.; González, E.; González, J.F.; González-García, C.M.; Ramiro, A.; Gañan, J. Thermal regeneration of activated carbon saturated with $p$-nitrophenol. Carbon 2004, 42, 2285-2293. [CrossRef]

34. Martin-Sanchez, N.; Soares, O.S.G.P.; Pereira, M.F.R.; Sanchez-Montero, M.J.; Figueiredo, J.L.; Salvador, F. Oxidative dehydrogenation of isobutane catalyzed by an activated carbon fiber cloth exposed to supercritical fluids. Appl. Catal. A Gen. 2015, 502, 71-77. [CrossRef]

35. Cooney, D.O.; Nagerl, A.; Hines, A.L. Solvent regeneration of activated carbon. Water Res. 1983, 17, $403-410$. [CrossRef]

36. Sutikno, T.; Himmelstein, K.J. Desorption of phenol from activated carbon by solvent regeneration. Ind. Eng. Chem. Fundam. 1983, 22, 420-425. [CrossRef]

37. Tamon, H.; Saito, T.; Kishimura, M.; Okazaki, M.; Toei, R. Solvent regeneration of spent activated carbon in wastewater treatment. J. Chem. Eng. Jpn. 1990, 23, 426-432. [CrossRef]

38. Martin, R.J.; Ng, W.J. The repeated exhaustion and chemical regeneration of activated carbon. Water Res. 1987, 21, 961-965. [CrossRef]

39. Martin-Sanchez, N.; Sanchez-Montero, M.J.; Izquierdo, C.; Salvador, F. Conversion of a resistant pollutant, phenol, into green fuels by gasification using supercritical water compressed up to 1000 bar. React. Chem. Eng. 2017, 2, 799-810. [CrossRef] 